\title{
Insomnia: psychological and neurobiological aspects and non-pharmacological treatments
} Insônia: aspectos psicológicos e neurobiológicos e tratamentos não farmacológicos

Yara Fleury Molen, Luciane Bizari Coin Carvalho, Lucila Bizari Fernandes do Prado, Gilmar Fernandes do Prado

\begin{abstract}
Insomnia involves difficulty in falling asleep, maintaining sleep or having refreshing sleep. This review gathers the existing informations seeking to explain insomnia, including those that focus on psychological aspects and those considered neurobiological. Insomnia has been defined in psychological (cognitive components, such as worries and rumination, and behavioral aspects, such as classic conditioning) and physiological terms (increased metabolic rate, with increased muscle tone, heart rate and temperature). From the neurobiological point of view, there are two perspectives: one which proposes that insomnia occurs in association with a failure to inhibit wakefulness and another that considers hyperarousal as having an important role in the physiology of sleep. The non-pharmacological interventions developed to face different aspects of insomnia are presented.
\end{abstract}

Keywords: insomnia, worry, attention-intention-effort pathway, hyperarousal, non-pharmacological treatment.

\section{RESUMO}

Insônia é um transtorno que envolve dificuldade em dormir, em manter-se dormindo ou em ter um sono restaurador. Esta revisão reúne informações que buscam explicar a insônia, incluindo aquelas que estudam os aspectos psicológicos e os neurobiológicos. A insônia tem sido definida em termos psicológicos (componentes cognitivos, tais como preocupações e ruminação e aspectos comportamentais, tais como o condicionamento clássico) e em termos fisiológicos (taxa metabólica aumentada, com tônus muscular, frequência cardíaca e temperatura aumentados). Do ponto de vista neurobiológico, há duas perspectivas: uma propondo que a insônia ocorre em associação com uma falha na inibição da vigília e outra que considera o hiperalerta como tendo um papel importante na fisiologia do sono. São apresentadas também as estratégias não farmacológicas desenvolvidas para lidar com os diferentes aspectos da insônia.

Palavra-chave: insônia, preocupação, caminho da atenção-intenção-esforço, hiperalerta, tratamento não farmacológico.

The word insomnia may signify - both for patients and for many physicians, merely the difficulty in falling asleep and a disorder of sleep loss. However, besides the patient's experiencing difficulty in initiating or maintaining sleep and poor quality of sleep, even with adequate opportunity and time, he also faces daytime impairment: fatigue, decreased concentration, attention or memory, low academic productivity, functional or professional impairment, besides mood disturbances or irritability, greater work absenteeism, decreased motivation, energy or initiative, tendency to errors and accidents at work or while driving, tension and worries about sleep. Despite these many manifestations promoting negative consequences on quality of life, there is still little dissemination of the knowledge about the impact of insomnia on the body of the patient, as there are no longer any doubts as to homeostatic changes related to insomnia, including increased mortality ${ }^{1}$.

Much is already known about the mechanisms of insomnia, with great scientific interest in identifying its neurobiological basis since the interaction between psychological states and metabolic and structural transformations of the nervous system is already widely accepted. As vast literature on insomnia approaches it in psychological, physiological and neurobiological terms, in this article the rational basis of various concepts of insomnia are reviewed in order to better understand it.

At the same time, the interventions available for nonpharmacological treatment are presented along with the 
characteristics that built our present knowledge about insomnia. This will allow the clinician to choose the most efficient and appropriate interventions.

\section{PREDISPOSING, PRECIPITATING AND PERPETUATING FACTORS}

Among the factors that can predispose an individual towards insomnia are: female gender, advanced age, a prior insomnia event, recurring depression and anxious personality. Stressful events may precipitate it: the loss of loved ones, financial crises, divorces, hospitalization or loss of a job. Physical problems such as pain or cancer, substances such as certain medications, disturbances in the circadian rhythm such as work shifts, anxiety due to the expectation of sleeping poorly and inadequate sleep habits, such as increased time in bed and alcohol consumption, also have an influence. Generally, sleep normalizes after the stress factor weakens or the person adapts to it. For some, however, sleep disruption may become chronic.

The precipitating factor, the original cause of insomnia, may be very different from the factors active when the patient seeks treatment. These are perpetuating or maintaining factors. The perpetuating processes increase gradually after the establishment of the disease ${ }^{2}$ and it is important to pay attention to them during treatment. Cognitive behavioral therapy for insomnia (CBTI) is a multicomponent nonmedication treatment targeting behavioral and cognitive factors that contribute to chronic sleep disturbances. The Spielman's "3 P" model ${ }^{3}$ allows an understanding of the role of cognitive behavioral therapy (CBT) in treating an insomniac: primarily, eliminates the perpetuating factors and then focus on the precipitating components.

Sleep Restriction and Stimulus Control are therapies dealing with perpetuating factors. These are the most effective single therapies for initiating and maintaining sleep, with average improvement rates of respectively $62 \%$ and $48 \%{ }^{4}$.

\section{Intervention: sleep restriction}

Sleep restriction focuses on limiting the time insomniac spend in bed while awake. This method involves establishing a sleep schedule. At first, total time in bed will be the typical short length of time patient usually sleeps. The sleep period is diminished to the permitted "sleep window". The schedule proposed might make insomniacs even more tired because some of the determined time in bed will be consumed trying to fall asleep. This tiredness helps the patient to getting to sleep more quickly. Over time, the length of time in bed is increased until a full night of sleep is achieved. Rising time is selected by the insomniac and used as an anchor. It is important delaying time to go to bed to respect the "sleep window". Week by week this sleep window may be incremented in 15 minutes in response to better sleep efficiency. Sleep efficiency is measured according to the following formula: total sleep time / total time in bed X 100. When sleep efficiency is greater than $85 \%$ for the previous week, increase in 15 minutes in total time in bed is proposed. When sleep efficiency is below $80 \%$, decrease in the same amount of time is done in the "sleep window". The sleep window should rarely be restricted to less than 4-5 hours.

\section{Intervention: stimulus control}

Bed, bedroom and bedtime are associated with sleep, except by insomniacs. For them, these stimuli are associated with worrying, watching TV, talking or studying in bed. These sleep interfering activities must be eliminated. The instructions given to the insomniacs involve going to bed only when they are sleepy; get out of bed if they are unable to sleep within 15-20 minutes and go to another room, engaging in some quiet activity, returning to bed only when sleepy; use bed and bedroom only for sleep and sex; do not watch TV, use the computer, play games, work, eat, smoke or worry in bed or bedroom, either during the day or at night; avoid daytime napping; maintain a regular arising time; get out of bed at the same time every morning, even in the weekends, no matter at what time did they went to bed in the previous night. Calm down one hour before bedtime, stopping activities and engaging in prebedtime rituals as bathing and decreasing of lightning is also recommended.

\section{BELIEFS AND ATTITUDES THAT WORSEN OR MAINTAIN INSOMNIA}

Insomnia is considered a result of dysfunctional cognitions, maladaptive behaviour (such as excessive time in bed and daytime napping), worries about the consequences of lack of sleep and arousal (physiological and cognitive).

\section{Physiological arousal}

Autonomic variables in insomniacs show high heart rate, in the pre-sleep period and during nocturnal sleep ${ }^{5}$ and change in heart rate variability (increased nighttime sympathetic activity and decreased parasympathetic activity ${ }^{6,7}$, elevated body temperature in elderly patients with insomnia at night, but not during the day ${ }^{8}$ and an increased basal metabolic rate ${ }^{9}$. These data showing the physiological arousal related with insomnia have led to many interventions willing to decrease such arousal. Relaxation and EMG biofeedback are very often utilized as psychological interventions for insomnia.

\section{Intervention: relaxation}

In progressive muscle relaxation, the alternating conscious repetition of muscle contraction and relaxation leads to a progressive relaxation and reduces anxiety. Abdominal 
breathing is frequently a component of various relaxation techniques, or it may be used alone. Relaxation therapy is useful for both sleep onset and maintenance insomnia (improvement rates averaging $41 \%$ and $28 \%$ respectively) ${ }^{4}$ and may require regular practice with a trained professional over a period of several weeks. When incorporated in daily life routine this practice brings long term beneficial results.

\section{Intervention: biofeedback}

Electromyography (EMG) biofeedback is a process that provides real time information from psychophysiological recordings about the levels at which physiological systems are functioning. Computers and other electronic devices are typically used in biofeedback. The EMG, a graphical representation recording neuronal activity in muscles anywhere in the body, provides feedback to patients about their levels of muscle tension and relaxation. Biofeedback treatment outcomes for sleep-onset insomnia are comparable to those obtained with relaxation and better results were shown for sleep-maintenance insomnia ${ }^{4}$.

\section{Cognitive arousal}

In chronic insomnia, the difficulties in sleep are accompanied by interpretations, beliefs, attitudes and behaviors that contribute in maintaining or worsening the sleep disturbance ${ }^{4}$. If temporary insomnia is considered a sign of danger or loss of control, and worries about the loss of sleep and its consequences become frequent, it will have more chances to become chronic.

Unrealistic expectations, distorted perceptions and worries may become dysfunctional and contribute to distress and maladaptive sleep habits, creating a tense state opposite to the relaxation necessary for sleep. The beliefs of the patient as to sleep and insomnia need to be analysed and eventually changed. Even if the patient reduces the time spent in bed, he may continue to have sleep disturbances because the hidden concepts as to the consequences of lack of sleep have not been covered in treatment. The patient may follow the therapy of stimuli control, but the concepts and beliefs that led him to carry out these practices should be understood and treated.

\section{Cognitive factors}

Some studies analyzed intrusive thoughts at night and the effects of emotionally loaded beliefs on the difficulty to sleep. Insomniacs tend to report having more negative thoughts about sleep, health, work and family during the presleep period and night arousals than controls that are good sleepers (CGS) ${ }^{10,11}$. Negative pre-sleep thoughts about not being able to sleep are associated with longer subjective sleep latencies ${ }^{10}$. Insomniacs tend to be more involved than CGS in self-monitoring activities (watching the clock, body sensations) and in safety behaviors (calculating the time left to sleep) ${ }^{11}$.

\section{Beliefs}

Young people may consider sleeping as wastage of time, belief that leads to restriction of sleep time and erratic sleep pattern. With sleep education teenagers and young adults may learn the importance of sleep in restoring the physical energy and psychic functions, dealing with emotional conflicts and other complex processes. Old adults may think they are sick if their sleep duration is near 6-6:30 hours. They must learn that the decrease in sleep duration is a common feature of population, with more than $50 \%$ sleeping less than 7 hours ${ }^{4}$.

\section{Intervention: cognitive therapy or cognitive restructuring}

Cognitive therapy involves identifying dysfunctional beliefs and attitudes about sleep and replacing them with more adaptive substitutes ${ }^{12}$. A way to find which are the wrong beliefs people nourish about insomnia is asking what are they thinking when they have difficulty in falling asleep. The answer may be: "It's 3 a.m. and I didn't sleep yet. I have only 3 hours to sleep and tomorrow I'll be very tired and slow at work!" Patients who think that insomnia is destroying their performance at work are encouraged to develop more adaptive coping skills and to stop critisizing themselves. These changes in attitudes often help to diminish anticipatory anxiety and arousal that interfere with sleep.

\section{WORRY IN THE MAINTENANCE OF INSOMNIA}

Regardless of the original cause, people with insomnia suffer with unpleasant intrusive thoughts during the presleep period ${ }^{13}$ and during wakefulness they have anxiety, worries, hyperarousal and tension².

In Harvey model ${ }^{13}$, the cognitive alert is the central axis. Excessive worry and rumination about not getting enough sleep and about the impact of the sleep disturbance on health and/or daytime function lead to activation of the sympathetic nervous system and anxiety. With an increase in autonomic activation, arousal and the appearance of distress, a selective attention may begin to perceive suggestions of threats related to sleep ${ }^{14}$. The insomniac remains attentive to internal (muscles tension) and external (the neighbor's dog that barks) phenomena unfavorable to sleep and focuses more on threatening cues connected with sleep.

The anxiety and the attention processes make the person believes that he had less sleep than he in fact did and/or that his daytime productivity was worse than it really was, that is, there is a "distortion of reality." Thoughts as "I did not get enough sleep" and "my output at work was way below standard" trigger preoccupations about becoming sick and losing the job.

\section{Worries}


Insomniacs go to bed worried about going to sleep quickly and getting the longest possible sleep. The determinant of their sleep disturbance is recognized by insomniacs as cognitive disturbance 10 times more often than somatic disturbance ${ }^{15}$. Cognitive items ("My mind keeps turning things over", "I am unable to empty my mind") were the answers with highest scores in the measurement of factors that contribute towards insomnia ${ }^{16}$. Excessive rumination concerning to the lack of sleep is the key aspect of the pre-sleep cognitive activities.

The pre-sleep cognitive activity of insomniacs is more negative than that of $\mathrm{CGS}^{17}$. Compared to healthy controls, primary insomnia patients showed both more sleep-related and general cognitive arousal, with sleep-related cognitive arousal closely associated with measures of sleep-onset and sleep-maintenance problem. General cognitive arousal did not show this association. Excessive worriness about insomnia itself exacerbates insomnia. Cognitive-behavioral treatment for insomnia (CBTI) might benefit from psychological interventions that are able to reduce sleep-related cognitive arousal.

\section{Intervention: imagery training}

Humans have an imagery system that is one of the most advanced components of the mind. In daily life people use imagery, without paying attention to the mechanisms involved. For instance, the way to arrive to a certain place is imagined before starting to drive. This mental exercise makes easier the driving itself. Imagery training for sleep aims at controlling intrusive thoughts and worries. In this way, the flow of negative cognitions and emotions - as fear of sleeplessness, fear of poor performance - may be interrupted. At cognitive level, these techniques may act through distraction or promotion of mastery and self-efficacy. Some studies have demonstrated that methods aiming cognitive arousal as imagery training produced slightly better results than those targeting somatic arousal, as progressive muscle relaxation and autogenic training ${ }^{18}$. During imagery training, the mind focuses on alternative themes such as visualized images or physiologic responses. It may be effective for thought processes that are anxiety-based or which flit from topic to topic. Attention-focusing procedures such as imagery training are intended at lowering intrusive thoughts and racing mind. Studies have demonstrated that pleasant and relaxing or symbolic imagery helped in the reduction of worries and arousal and reduced sleep onset latency ${ }^{19}$, other sleep variables $^{20}$ and $\operatorname{mood}^{21}$ in individuals with insomnia. Our own experience with guided imagery in insomnia has shown that changes in psychological arousal may happen very quickly and that disturbing emotions may be worked out and overcome. For example, a patient that was unable to go back to sleep after waking up in the middle of the night before the 20 years old daughter arrived home on week-end night's, after one session with guided imagery reported no more sleep problems during the weekends.

\section{Selective attention and monitoring}

Monitoring includes paying attention to car sounds, birds singing, external lightning. Monitoring the clock is associated with greater sleep latency and more worry about sleeping ${ }^{22}$. Those who monitor the clock also overestimated the sleep onset latency. It is possible that monitoring the clock contributes toward the distortion of sleep perception. It seems that monitoring is automatic, using a minimum of attention resources and happening without a conscious decision to do so. Insomniacs frequently claim that their sleep is light and it is related to the monitoring activity they maintain even when sleeping. By distraction of attention the monitoring activity may decrease and deep sleep may improve.

\section{Intervention: distraction of attention}

Distraction of attention is a technique that deviate cognitive activity from worries to neutral subjects. A specific distractor draws attention away from unwanted thoughts ${ }^{11}$ and monitoring. Replacing worries with engaging tasks as challenging mental arithmetic problems reduced subjective sleep latency among insomniacs ${ }^{5}$. Reading, crossword puzzles, sudoku puzzle practiced before sleep, at bed, are strategies frequently used for coping with insomnia.

\section{Distorted perception}

The duration of sleep in good sleepers and insomniacs is not so different to justify the severity of their complaints ${ }^{23}$. In reality, the tendency to overestimate sleep latency and underestimate the total time of sleep is almost always present in insomnia ${ }^{24}$. Distortions in the estimate of the pre-sleep period time may be a direct result of worries.

\section{Safety behaviours}

The strategies developed by insomniacs to avoid the fear of not getting to sleep are called safety behaviours, which prevent the disconfirmation of inappropriate beliefs and include thought control. Insomniacs complain of ruminative, intrusive and uncontrollable thinking during the pre-sleep period ${ }^{11}$ and report trying to suppress these thoughts during this period ${ }^{25,26}$. The tentative of suppressing rumination may result in greater latency and worse quality of sleep ${ }^{26}$. The safety behaviours prevent the disconfirmation of inappropriate beliefs. An example of a safety behavior is remaining in bed well beyond the normal rising time, instead of getting up in the usual time, after a poor night sleep, believing that this is a solution for the daily performance fear. However, this will maintain the sleep problem during the next night: although the person will be sleepy latter, the time to go to bed will be the same or earlier, leading, as a result, to a longer latency. In this way there is a confirmation of the sleep difficulties. When there is a poor sleep night but the 
time of leaving the bed is stable, next night the person will be sleepy and latency will be shorter, disconfirming the belief that staying longer in bed is helpful for sleep disturbance.

\section{Real deficit}

The excessive anxiety can end in a true deficit, because initiating sleep with catastrophic worry, physiological arousal and anxiety is not ease and this can affect daytime function.

\section{Intervention:cognitive control or thought control}

For many people, time in bed is time of thinking about life. During daytime, activities and thoughts are related to work and duties. At night, there is the possibility of thinking on the things to do. Such mental activity awakens and is incompatible with successful sleep. Analyzing the past day may bring the emotions involved to surface and putting them to rest, may be calming and relaxing. Preparing an agenda for the following day, some hours before going to bed (around 7 pm) and writing down on a paper a list of "what to do", can be very helpful in giving rest to the mind in bed. Leaving pen and paper at the bedside and writing down any new idea that can disturb the sleep, may allow thoughts to weaken and quieting.

\section{INSOMNIA OCCURS WITH ATTENTION- INTENTION-EFFORT}

Insomnia could be the result of the inhibition of deactivation (de-arousal) processes of normal sleep ${ }^{27}$. The contrast between normal sleep and insomnia is the main aspect in this approach. There are cognitive differences between normal sleep and psychological insomnia. Normal sleep is a process of decreased arousal (de-arousal) without impediments, allowing homeostatic and circadian needs to automatically lead to sleep. Insomnia would be a product of increased arousal, associated with efforts to sleep. Normal sleep, a relatively involuntary psychophysiological process, may be affected by focused attention and direct attempts to control its expression.

The cognitive attention-intention-effort (AIE) approach ${ }^{28,29}$ suggests that persistent insomnia results from a deviation of selective attention to sleep, leading to an active intention to sleep and originating an effort-to-sleep syndrome. When the role of attention bias in the development from acute to persistent insomnia was examined ${ }^{30}$, worries related to sleep were associated with this transition. The attention bias would help in the maintenance and triggering of primary insomnia. Inhibition of automatism may cause psychophysiological insomnia and, at an extreme, the AIE syndrome, a subtype of insomnia, may exist ${ }^{28}$.

\section{Intervention: paradoxal intention}

If the insomniac makes unfruitful efforts to sleep with tension and anxiety as the only result, the clinician recommendation not to sleep can remove a big burden from his shoulders. In this case, the performance anxiety that inhibits sleep onset is weakened or disappears. The intention to remain passively awake without any effort to fall asleep may permit the calm environment needed for relaxation and sleep. Paradoxal intention is an intervention with moderate degree of clinical effectiveness ${ }^{31}$.

\section{HYPERAROUSAL IN INSOMNIA}

Neurophysiological differences found between normal sleep and that of the insomniac have shown that insomnia is a physiological phenomenon accompanied by increased autonomic activity $^{32,33}$. Arousal manifests as somatic (shortness of breathing, cold feet, dry mouth), cognitive (thoughts that do not stop) and cortical activation. Cortical arousal is experienced subjectively as an increase in cognitive activity and is measurable on the electroencephalogram (EEG) as increased fast frequencies of the sleep EEG. Differently from normal sleepers, which have these processes diminishing during the peri-sleep period, the individual with insomnia may be forming long term memories and sensory and information processing during this period.

Perlis et al..$^{32,33}$ defined as "neurocognitive theory of insomnia" the extensive review that they elaborated taking into consideration hyperarousal, including neurobiological variables (neuroendocrine and neuroimmune changes) as well as structural and functional brain alterations and the evidences relating insomnia to hyperarousal. This hyperarousal model ${ }^{34}$ considers that chronic insomnia may have an important role in the development of depression, addiction, and anxiety disorders. Compared to CGS subjects, patients with insomnia have greater dependency on alcohol or hypnotic or sedative drugs. Insomnia may result from dysfunctional cognitive processes that lead to physiological hyperarousal and produces high levels of sensory and information processing, and of long-term memory formation. At the same time, insomnia partially results from a genetically determined dysfunction in the neural sleep-wakefulness circuit, which originates in the brain and leads to interruption of sleep and to cognitive and emotional disorders.

\section{Intervention: mindfulness meditation}

Mindfulness meditation is a new approach to stress management and emotion regulation that has being beneficial to insomnia. Mindfulness meditation combined with CBT for insomnia ${ }^{35}$ showed statistically and clinically significant reductions in pre-sleep arousal, sleep effort and dysfunctional sleep-related cognitions. Changes demonstrated a significant correlation between number of meditation sessions and measured arousal. The principles of mindfulness - letting go, acceptance and non-striving - encourage participants to observe their thoughts and feelings and culminate in reducing arousal. 
Daytime performance and consolidation of nighttime memory in insomnia

Studies on brain plasticity and memory consolidation showed impairments in the consolidation of memory $\mathrm{y}^{36} \mathrm{in} \mathrm{pa-}$ tients with primary insomnia (PI) compared to CGS. Studies investigating daytime performances frequently do not detect great impairments, despite the complaints of insomniacs. Objective measures of cognitive performance in insomni$\mathrm{ac}^{37,38}$ concluded that there is a small deficit in this population, with a significant difference in relation to the control group in only $20-25 \%$ of all comparisons.

\section{Intervention: exercise}

There is evidence that exercise can have a beneficial effect on sleep quality. Research ${ }^{39}$ has shown that many aerobic or resistance exercise may be a supported intervention for insomnia in a clinical practice, allowing the patient to select it according to his preference. A chinese exercise program with Tai Chi Chih ${ }^{40}$ and a forest walking ${ }^{41}$ improved sleep quality in insomniacs. The practice of Bikran yoga ${ }^{42}$ during a 14-day period was associated with significantly faster return to sleep after nocturnal awakenings. In patients with non-remitted major depressive disorder, exercise augmentation resulted in improvements in self-reported sleep quality ${ }^{43}$. As insomnia is often a residual symptom after major depression treatment and an associated risk of depression recurrence, exercise augmentation may be an important intervention in the treatment of depression with insomnia. In our clinical practice patients have greatly benefited also from swimming and dancing activities. Morning exercise can encourage early and constant waking time and early morning light exposure, important to restructure sleep patterns on a daily basis. For elder people, whose energy consumption after retirement may decrease, recommendation of physical exercise may be an useful way of increasing sleep quality due to a tiring daily activity.

\section{Consequences of primary insomnia for psychopathology}

Insomnia due to a mental disorder, is the most common diagnosis among those who seek medical evaluation / treatment in sleep disorders' centers. Insomnia symptoms and depressive and anxiety problems frequently coexist. Investigating the patient's history, the course of the insomnia symptoms correlates to the course of the underlying mental disorder. Insomnia may be the first expression of the underlying mental disorder, and patients often attribute their mental problems to poor sleep. Sometimes, it may be difficult for the clinician to determine if insomnia is a manifestation of some mood or anxiety disorder, or if it is a cause for depressive and anxiety symptoms.

Insomnia - depression
Around $90 \%$ of depressed patients complain of the quality of their sleep. Insomnia is the most common symptom of depression and anxiety. However, the Annals of the Conference on the State of the Science on insomnia ${ }^{44}$ of the American National Institutes of Health, consider insomnia not only a symptom of depression, but an independent risk factor for its development ${ }^{34,45}$ since insomniacs have 2 to 4 times the risk of becoming depressed. Insomnia is also a risk factor for bad depression outcomes. Depressed patients who received standard treatment with anti-depressives and an additional help ${ }^{46,47}$ showed that the additional treatment of insomnia (with hypnotic or CBT for insomnia) enhanced the improvement of depression, emphasizing that insomnia treatment in patients with depression may have a favorable impact on the trajectory of the disease.

\section{Addiction}

\section{Hypnotic dependence}

Benzodiazepines are widely used in medical practice for the treatment of sleep disorders. However, long-term use may cause dependence and addiction. Dependence is characterized by tolerance and withdrawal. Tolerance may develop with nightly utilization and increase in dosage is needed to have the hypnotic effect, till the maximum safe dosage is reached. The attempts to discontinue the medication or abruptly reduce it will end in rebound insomnia, with worsening of sleep problems above baseline levels. The belief that medication is really necessary makes patients resume its use. Short-term use of hypnotics is indicated for acute insomnia, jet lag, severe insomnia due to another sleep disorder as restless legs, an acute medical condition such as pain or selected psychiatric disorders ${ }^{4}$.

\section{Alcoholism}

It is well known that alcohol may deepen sleep and decrease REM sleep at the beginning of the night, with an increase of REM sleep and of awakenings at the end of the night. One of the self-help maladaptive practices insomniacs engage is substance abuse, mainly self-medication with alcohol. Compared with healthy people, insomniacs more commonly drink alcohol before going to bed ${ }^{48}$. Some research results suggest that drinking alcohol is an important risk factor for sleep problems. On the other hand, sleep problems may predispose to developing alcohol problems. Sleep difficulties may enhance the risk of relapse among abstinent alcoholics ${ }^{49,50}$. Clinicians should take interest and care in investigating the use of alcohol with patients who complain about insomnia.

NON-PHARMACOLOGICAL INTERVENTIONS PROS AND CONS 
Cognitive Behavior Therapy (CBT) is considered, together with pharmacological option, the standard treatment for insomnia $^{51,52}$. In the long run, CBT outcomes are better than medicine utilization, because the patient changes habits, behaviors and beliefs that enhance sleep quality. Behavioral therapies take a few weeks to improve sleep but keep on giving results after training sessions have been terminated. On the other hand, pharmacological treatment, if suddenly stopped, brings rebound insomnia. Research in the area of treatment preference demonstrates that insomniacs tend to prefer behavioral over pharmacological treatments ${ }^{53,54}$.

However, CBT is not commonly recommended by clinicians and many reasons can contribute to this situation. Many clinicians are not informed about the practices of psychological treatment and do not use them with their patients. Clinicians should be in touch with psychological research support in order to utilize this tool with their own patients. Furthermore, CBT therapists are not always available. Other professional areas, as primary care nurses ${ }^{55}$, are nowadays being trained and supervised to face the demand of instructing patients with insomnia through CBT sessions in routine general medical practice. High costs of individualized CBT sessions are considered another obstacle to its spread as a way to deal with sleep difficulties. Group therapy can be offered as a cost solution. Self-help treatment with manuals, booklets or pamphlets is an alternative manner of targeting more patients and frequently is the only option available.

\section{Intervention: self-help programs}

Supported as well as unsupported programs can be offered with many conveniences, as availability and short treatment duration besides the financial cost of treatment being reduced. Unsupported self-help intervention (SHI), either electronic or paper-and-pencil format compared to a waiting list showed moderate to large effects on sleep measures till
48 weeks after treatment ${ }^{56}$. A CBT self-help book is effective to treat insomnia and the effect is enhanced by adding brief therapist telephone support ${ }^{57}$. Such a program can also be conducted in combination with pharmacotherapy. In a study with primary insomnia participants ${ }^{58}$, one group received a progressively reduced 4-week pharmacotherapy while the other group intervention was a combination of pharmacotherapy and a SHI consisting of six chapters on progressive muscle relaxation, modified stimulus control, thought stopping and cognitive restructuring. Reduction of sleep onset latency (SOL) and wake after sleep onset (WASO) were found in the whole sample. Total sleep time increased and depression improved. Patients additionally with SHI had significantly more improvement in sleep, rumination and focusing on sleep till six- month follow-up. Outcome from a metaanalysis study ${ }^{59}$ showed that self-help treatment improves sleep (sleep onset latency, wake after sleep onset, sleep quality and sleep efficiency), depression and anxiety. The effects are moderate and remain stable over time.

Computerised cognitive behavioural therapy (CCBT) is an innovative mode of delivering services to patients with psychological disorders. A meta-analysis ${ }^{60}$ to review and evaluate the effectiveness of CCBT for insomnia (CCBT-I) found it a mildly to moderately effective self-help therapy in the short run for insomnia. Self-help insomnia treatments may be appropriate for patients with less severe insomnia and those without comorbid disorders. CCBT-I can be a type of low-intensity treatment in the stepped care model ${ }^{61}$ for insomnia.

In conclusion, insomnia is a 24-hour disease understood as a neuropsychobiological disorder associated not only with psychological alterations. A multidimensional evaluation of insomnia with sleep history, medical history, drugs/substances use and psychiatric assessment has been emphatically pointed for many years and must be done thoroughly. The therapeutic approach in insomnia should also be multidimensional

\section{References}

1. Vgontzas AN, Liao D, Pejovic S, et al. Insomnia with short sleep duration and mortality: the Penn State cohort. Sleep 2010;9:1159-1164.

2. Spielman AJ, Caruso LS, Glovinsky PB. A behavioral perspective on insomnia treatment. Psychiatr Clin North Am 1987;10:541-553.

3. Spielman AJ, Glovinsky P. The varied nature of insomnia. In: P J Hauri (Ed..), Case studies in insomnia. New York: Plenum Press 1991:1-15.

4. Morin CM. Insomnia. Psychological assessment and management. New York: Guilford Press; 1993.

5. Haynes SN, Adams A, Franzen M. The effects of pre-sleep stress on sleep onset insomnia.J Abnor Psychol 1981;90:601-606.

6. Bonnet $\mathrm{MH}$, Arand $\mathrm{DL}$. Heart rate variability in insomniacs and matched normal sleepers. Psychosom Med 1998;60:610-615.

7. Fang SC, Huang CJ, Yang TT, Tsai PS. Heart rate variability and daytime functioning in insomniacs and normal sleepers: preliminary results. $J$ Psychosom Re 2008;65:23-30.
8. Lack LC, Gradisar M, van Someren EJW, Wright HR, Lushington K. The relationship between insomnia and body temperatures. Sleep Med Rev 2008;12:307-317.

9. Bonnet $\mathrm{MH}$, Arand DL. 24-Hour metabolic rate in insomniacs and matched normal sleepers. Sleep 1995;18:581-588.

10. Fichten CS, Libman E, Creti L, Amsel R, Tagalakis V, Brender W. Thoughts during awake times in older good and poor sleepers-the self-statement test: 60+. Cognit Ther Res 1998;22:1-20.

11. Harvey AG. Pre-sleep cognitive activity in insomnia: a comparison of sleep-onset insomniacs and good sleepers. Br J Clin Psychol 2000;39:275-286.

12. Morin CM, Espie CA. Insomnia - a clinical guide to assessment and treatment. New York: KluwerAcademic/Plenum Publishers; 2003.

13. Harvey AG. A cognitive model of insomnia. Behav Res Ther 2002; 40:869-893. 
14. Semler CN, Harvey AG. An investigation of monitoring for sleep-related threat in primary insomnia. Behav Res Ther 2004;12:1403-1420.

15. Lichstein KL, Rosenthal TL. Insomniacs' perceptions of cognitive versus somatic determinants of sleep disturbance. J Abnorm Psychol 1980;1:105-107.

16. Espie CA, Brooks DN, Lindsay WR. An evaluation of tailored psychological treatment of insomnia. J Behav Ther Exp Psychiatry 1989;2:143-153.

17. Kuisk LA, Bertelson AD, Walsh JK. Pre-sleep cognitive hyperarousal and affect as factors in objective and subjective insomnia. Percept Mot Skills 1989;69:1219-1225.

18. Morin CM, Bootzin RR, Buysse DJ, et al. Psychological and behavioral treatment of insomnia: update of the recent evidence (1998-2004). Sleep 2006;11:1398-1441.

19. Harvey AG, Payne S. The management of unwanted pre-sleep thoughts in insomnia: distraction with imagery versus general distraction. Behav Res Ther 2002;3:267-277.

20. Molen YF, Carvalho LBC, Carvalho JEC, Barreto LA, Prado LBF, Prado GF. Imagery rehearsal therapy improves sleep. Sleep 2007;30: 271.

21. Molen, YF, Carvalho LBC, Carvalho JEC, Barreto LA, Prado LBF, Prado GF. Insomnia treatment with imagery rehearsal therapy. Sleep 2007;30:272.

22. Harvey AG, Schmidt DA. Clock monitoring in the maintenance of insomnia. Sleep 2001;24(Suppl):S334-S335.

23. Adams K, Tomeny M, Oswald I. Physiological and psychological differences between good and poor sleepers. J Psychiatric Res 1986;20:301-316.

24. Bonnet $\mathrm{MH}$. The perception of sleep onset in insomniacs and normal sleepers. In: Bootzin RR, Kihlstrom JF, Schacter DL(Eds.). Sleep and Cognition. Washington, DC: American Psychological Association; 1990:148-158.

25. Harvey AG. Insomnia: symptom or diagnosis? Clin Psychol Rev 2001;7:1037-1059.

26. Harvey AG. The attempted suppression of pre-sleep cognitive activity in insomnia. Cognit Res Ther 2003;6:593-602.

27. Espie CA. Insomnia: Conceptual issues in the development, persistence, and treatment of sleep disorders in adults. Annu Rev Psychol 2002;53:215-243.

28. Espie CA, Broomfield NM, MacMahon K, Macphee LM, Taylor LM. The attention-intention-effort pathway in the development of psychophysiologic insomnia: a theoretical review. Sleep Med Rev 2006;10:215-245.

29. Espie CA. Understanding insomnia through cognitive modeling. Sleep Med 2007;8(Suppl):S3-S8.

30. Taylor LM, Espie CA, White CA. Attentional bias in people with acute versus persistent insomnia secondary to cancer. Behav Sleep Med 2003;4:200-212.

31. Chesson AL, Anderson WM, Littner M, et al. Practice parameters for the nonpharmacological treatment of chronic insomnia. Sleep 1999;22:1128-1133.

32. Perlis ML, Giles DE, Mendelson WB, Bootzin RR, Wyatt JK. Psychophysiological insomnia: The behavioural model and a neurocognitive perspective. J Sleep Res 1997;6:179-188.

33. Perlis ML, Pigeon WR. The neurobiology of insomnia. In: Drummond SP (Ed.). Neurobiology of disease. Burlington, MA: Elsevier; 2006:735-744.

34. Riemann D, Spiegelhalder K, Feige B, et al. The hyperarousal model of insomnia: a review of the concept and its evidence. Sleep Med Rev 2010;14:9-31.

35. Ong JC, Shapiro SL, Manber R. Combining mindfulness meditation with cognitive-behavior therapy for insomnia: a treatmentdevelopment study. Behav Ther 2008;2:171-182.

36. Nissen C, Kloepfer C, Nofzinger EA, Feige B, Voderholzer U, Riemann D. Impaired sleep-related memory consolidation in primary insomnia. Sleep 2006;29:1068-1073.
37. Riedl BW, Lichstein KL. Insomnia and daytime functioning. Sleep Med Rev 2000;4:277-298.

38. Fulda S, Schulz H. Cognitive dysfunctions in sleep disorders. Sleep Med Rev 2001;5:423-445.

39. Yang PY, Ho KH, Chen HC, Chien MY. Exercise training improves sleep quality in middle-aged and older adults with sleep problems: a systematic review. J Physiother 2012;3:157-163.

40. Irwin MR, Olmstead R, Motivala SJ. Improving sleep quality in older adults with moderate sleep complaints: a randomized controlled trial of Tai Chi Chih. Sleep 2008;7:1001-1008.

41. Morita E, Imai M, Okawa M, Miyaura T, Miyazaki S. A before and after comparison of the effects of forest walking on the sleep of a community-based sample of people with sleep complaints. Biopsychosoc Med 2011;5:13.

42. Kudesia RS, Bianchi MT. Decreased nocturnal awakenings in young adults performing bikram yoga: a low-constraint home sleep monitoring study. ISRN Neurol 2012;1212:153745.

43. Rethorst CD, Sunderajan P, Greer TL, et al. Does exercise improve selfreported sleep quality in non-remitted major depressive disorder? Psychol Med 2012;29:1-11.

44. $\mathrm{NIH}$. National Institutes of health state of the science conference statement: manifestations and management of chronic insomnia in adults. Sleep 2005;28:1049-1057.

45. Pigeon WR, Perlis ML. Insomnia and depression: birds of a feather? Int J Sleep Disord 2007;1:82-91.

46. Fava M, Mc Call WV, Krystal A, et al. Eszopiclone co-administered with fluoxetine in patients with insomnia coexisting with major depressive disorder. Biol Psychiatry 2006;59:1052-1060.

47. Manber R, Edinger J, Gress JL, Pedro-Salcedo S, Kuo TF, Kalista T. Cognitive behavioural therapy for insomnia enhances depression outcome in patients with comorbid major depressive disorder and insomnia. Sleep 2008;31:489-495.

48. Brower KJ, Aldrich MS, Robinson EAR, Zucker RA, Greden JF. Insomnia, self-medication, and relapse to alcoholism. Am J Psychiatry 2001;3:399-404.

49. Brower KJ. Insomnia, alcoholism and relapse. Sleep Med Rev 2003;6:523-39.

50. Brower KJ, Krentzman A, Robinson EA. Persistent insomnia, abstinence, and moderate drinking in alcohol-dependent individuals. Am J Addict 2011;5:435-440.

51. Morin CM, Hauri PJ, Espie CA, Spielman AJ, Buysse DJ, Bootzin RR. Nonpharmacologic treatment of chronic insomnia. Sleep 1999;22:1134-1156

52. Morgenthaler T, Kramer M, Alessi C, et al. Practice parameters for the psychological and behavioral treatment of insomnia: An update. An American Academy of Sleep Medicine Report. Sleep 2006;29:1415-1419.

53. Morin CM, Gaulier B, Barry T, Kowatch RA. Patients' acceptance of psychological and pharmacological therapies for insomnia. Sleep 1992;15:302-305.

54. Vincent N, Lionberg C. Treatment preference and patient satisfaction in chronic insomnia. Sleep 2001;24:411-417.

55. Espie CA, MacMahon KMA, Kelly HL, et al. Randomized clinical effectiveness trial of nurse-administered small-group cognitive behavior therapy for persistent insomnia in general practice. Sleep 2007;30:574-584.

56. Lancee J, van den Bout J, van Straten A, Spoormaker VI. Internetdelivered or mailed self-help treatment for insomnia?: a randomized waiting-list controlled trial. Behav Res Ther 2012;1:22-29.

57. Jernelöv S, Lekander M, Blom K, et al. Efficacy of a behavioral selfhelp treatment with or without therapist guidance for co-morbid and primary insomnia - a randomized controlled trial. BMC Psychiatry 2012;12:5. 
58. Katofsky I, Backhaus J, Junghanns K, et al. Effectiveness of a cognitive behavioral self-help program for patients with primary insomnia in general practice - a pilot study. Sleep Med 2012;5:463-468.

59. van Straten A, Cuijpers P. Self-help therapy for insomnia: a metaanalysis. Sleep Med Rev 2009;1:61-71.
60. Cheng SK, Dizon J. Computerised cognitive behavioural therapy for insomnia: a systematic review and meta-analysis. Psychother Psychosom 2012;4:206-216.

61. Espie CA. "Stepped Care": a health technology solution for delivering cognitive behavioral therapy as a first line insomnia treatment. Sleep 2009;12:1549-1558. 


\section{Correction}

Arq Neuropsiquiatr 2014;72(01):63-71

Insomnia: psychological and neurobiological aspects and non-pharmacological treatments

\section{Page 65}

Where it is written:

Intervention: cognitive therapy or cognitive reconstructuring

It should be:

Intervention: cognitive therapy or cognitive restructuring 